\title{
Traumatic fracture of contact lens with corneal injury
}

\author{
P. J. O'ROURKE \\ Kent County Ophthalmic and Aural Hospital, Maidstone
}

There are few reports of the action of contact lenses modifying the effects of injury to the eye. The increasing popularity of contact lenses and the growing risk of serious road accidents have suggested the publication of this case in which traumatic fracture of a contact lens caused a moderately severe and unusual corneal injury.

\section{Case report}

A Danish girl aged 19 was involved in a road traffic accident in December, 1969. At the time of the accident she was wearing plastic corneal contact lenses for the correction of simple myopia. She was unconscious for some time and later could give no details of exactly what happened other than that she was the front seat passenger and not wearing a safety belt.

\section{Examination}

There was a partial thickness laceration of the right cornea at the junction of the middle and lower thirds extending in an irregular horizontal line from side to side. From the depth of this laceration the cornea was split to the lower limbus and in the lamellar pocket so formed were embedded multiple fragments of a shattered corneal contact lens. At no point did this lamellar laceration penetrate the full thickness of the cornea. Above this wound and towards the nasal side of the cornea was a smaller, partial thickness laceration of the cornea, also containing fragments of contact lens and again not penetrating the full thickness of the cornea. There was also an irregular conjunctival laceration temporal to the limbus and a small hyphaema. There were also multiple lacerations of the eyelids and face most of which contained fragments of shattered windscreen. The left eye was uninjured.

\section{Operation}

That same evening the right corneal lacerations were sutured and with the aid of the operating microscope as many as possible of the fragments of contact lens were removed from the lamellar pocket in the cornea. Fragments of contact lens were also removed from the right upper fornix. An intact contact lens was removed from the left eye which was undamaged. The various lid and facial lacerations were sutured after removal of the shattered windscreen fragments.

Result

The patient made an uninterrupted recovery, the lid and facial sutures being removed on the fourth day, and the corneal sutures on the tenth day.

\section{Follow-up}

After 7 months the findings were as follows:

RIGHT EYE Visual acuity 6/9, with $-5 \mathrm{D}$ sph.

LEFT EYE Visual acuity $6 / 6$, with $-4.75 \mathrm{D}$ sph. 
The right cornea had healed satisfactorily, leaving an irregular, horizontal, partial-thickness scar, passing across the lower part of the pupil with some very small fragments of contact lens still embedded in the stroma (Figure). The eye was white and quiet and the patient symptom free.

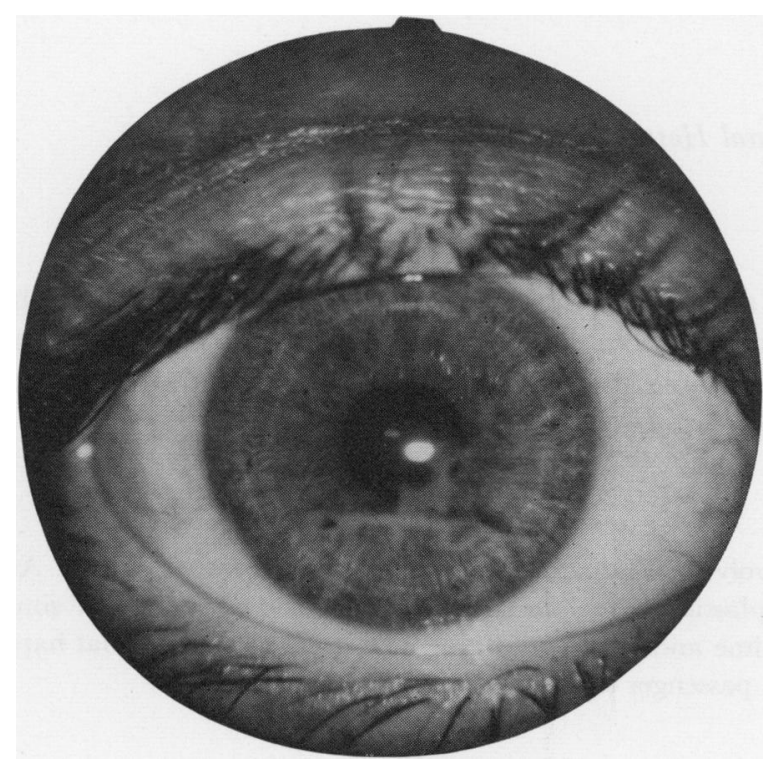

FIGURE Appearance of the injured eye 7 months after operation

\section{Comment}

Previous reports of a fractured contact lens modifying the effects of eye injury include three cases of corneal abrasion of an eye with a contact lens caused by a blow from a fist (Brown, I964). In each case the lens broke into several large pieces only, those remaining in the eye were always found in the upper fornix, and the abrasions healed rapidly and completely without visual loss.

There is one reported case of traumatic dislocation of a contact lens into the eyelid, again caused by a blow from a fist (Shenken, 1969). In this case the contact lens was "lost" for 40 months after the injury, the patient experiencing only mild intermittent conjunctivitis. Finally a swelling of the outer upper eyelid developed and an intact corneal contact lens was removed from within the tissues of the eyelid by incision from the conjunctival surface. A similar case of a contact lens "lost" for a year and eventually found embedded in the tissues of the upper eyelid and needing surgical removal has been reported (Michaels and Zugsmith, 1963), but with no mention of trauma as a precipitating cause.

A most unusual case following severe injuries to the trunk and face with extensive skull and facial fractures was reported by Podos and Freeman (1965). The eyelids were swollen and ecchymotic except for a central round clear area in one upper lid which was found to overlie a contact lens trapped between the lid and globe. The cornea was uninjured. It was postulated that the presence of a contact lens between the globe and the lid prevented blood flowing into the lid over the lens thus maintaining a circular blood-free area. This was suggested as a diagnostic sign in head trauma with wearers of contact lenses. 
On the other hand protection of the eye by a contact lens from possible severe injury has also been reported. Györffy (195I) described four such cases: in one a high-velocity metal splinter lodged in a contact lens without fracturing it and without causing ocular damage, in another the contact lens was badly scratched by a thorn without ocular damage, and in two cases fist injuries led to severe periorbital haematoma (with loss of consciousness in one) without corneal injury or fracture of the lenses. Three other cases reported by Brown (1964) included a contact lens cracked right through by a highvelocity shotgun pellet without corneal injury, a high-velocity metal splinter penetrating a contact lens and causing a partial-thickness laceration of the stroma which healed with minimal scarring, and corneal abrasions of an aphakic eye with fracture of the contact lens when it was struck by a nail.

In the present case one can only speculate that the patient's head struck the windscreen violently, embedding the lower edge of the contact lens in the cornea, and that the divergence of the stress by the contact lens shattered it before the cornea was completely perforated.

\section{Summary}

A case of traumatic fracture of a contact lens with corneal injury is presented together with a review of the literature.

The photograph was taken by Mr. P. Broadberry, Department of Medical Photography, Queen Victoria Hospital, East Grinstead, Surrey.

\section{References}

BRown, D. v. L. (1964) Arch. Ophthal. (Chicago), 72, 319

GYÖRFFY, s. (195I) Ophthalmologica (Basel), 122, 344

Michaels, D. D., and zugsmith, G. s. (1963) Amer. F. Ophthal., 55, 1057

PODOS, S. M., and FREEMAN, M. I. (1965) Ibid., 60, 148

shenken, e. (1969) Canad. med. Ass. J., ror, 295 